\title{
Lesson in implementing sustainability courses into the engineering curricu- lum
}

\section{Dr. Bradley A. Striebig, James Madison University}

Dr. Striebig is a founding faculty member and first full professor in the Department of Engineering at James Madison University. Dr. Striebig is a founder and member of Water for Africa a 501c3 non-profit organization. Dr. Striebig came to the JMU School of from Gonzaga University where he developed the WATER program in cooperation with other faculty members. Dr. Striebig is also the former Head of the Environmental Technology Group at Penn State's Applied Research Laboratory. In addition to Dr' Striebig's engineering work, he is also a published freelance photographer who has works with local and international NGOs. Dr. Striebig was the founding editor of the Journal of Engineering for Sustainable Development and an assistant editor for the Journal of Green Building.

\section{Dr. Maria Papadakis, James Madison University \\ Dr. Adebayo Ogundipe, James Madison University}

Adebayo Ogundipe is an Assistant Professor in the Department of Engineering at James Madison University (JMU). His research is on developing tools and protocols for assessing sustainable engineering designs using life-cycle assessment and industrial ecology methods. Dr. Ogundipe's prior work includes DOD funded research on assessing the sustainability of proposed U.S. Military munitions as well as development of decision tools for the assessment of green and sustainable remediation. He is currently actively involved in development and teaching of technical content for sustainability courses and modules in the Department of Engineering at JMU. Dr. Ogundipe holds a Ph.D. in Environmental Engineering, an M.Eng in Chemical Engineering from Stevens Institute of Technology, and B.Sc. in Chemical Engineering from the University of Lagos, Nigeria.

\section{Dr. Samuel Albert Morton III, James Madison University}

Samuel Morton is an Assistant Professor of Engineering at James Madison University. Prior to joining the faculty of engineering, Dr. Morton was a Senior Research Engineer at the Center for Applied Research at the University of Kentucky, specifically in the Biofuels and Environmental Catalysis Group. Dr. Morton has teaching experience from his time as an Assistant Professor of Chemical Engineering at Lafayette College and as an Adjunct Professor of Chemistry at Eastern Kentucky University. During Dr. Morton's tenure at Lafayette College he taught various undergraduate courses such as Process Design Synthesis, Green Engineering and Unit Operations. Currently he teaches courses in Sustainability, Green Engineering, and Engineering Management. He received a BS in Chemical Engineering from Tennessee Technological University in 1996, a MS in Chemical Engineering from the University of Tennessee Space Institute in 1998, and a PhD in Chemical Engineering from the University of Tennessee in 2004. He is a registered Professional Engineering in the Commonwealth of Kentucky. 


\title{
Lesson in implementing sustainability courses into the engineering curriculum
}

\begin{abstract}
This paper describes a newly accredited Bachelor of Science in Engineering degree requiring the completion of a two-course sequence in sustainability. The sustainability courses are the first significant exposure for undergraduate engineering students to sustainability, environmental impacts, and industrial ecology. This paper will discuss the lessons learned after four years of offering the two-course sustainability sequence in a general engineering curriculum.

The first offerings of the sustainability courses identified students lacked the requisite understanding of applied chemistry and thermal sciences needed to fully understand potential anthropogenic impacts to the environment and broader sustainability issues. Students also noted dissatisfaction with the available textbooks, being frustrated by either a lack of quantitative examples or an overemphasis on waste treatment. Implementation of the combination of the following course modifications noticeably increased students' understanding of sustainability:
\end{abstract}

- More extensive pre-requisites for general chemistry and thermo sciences were required.

- A sustainable engineering textbook and workbook were adopted.

- Literature on sustainability and engineering outcomes was adopted, as it became more broadly available.

- Class time was focused more on student work time and question and answer time, with heavier reliance placed upon reading and independent study time for gaining information about the course content.

Remaining challenges include, determining and adapting to prerequisites for the course, adapting the courses to the evolving engineering curriculum, and prioritizing topics to be covered.

Background

Sustainability is important in manufacturing, construction, planning and design. Alleby et. al. state that: "Sustainable engineering is a conceptual and practical challenge to all engineering disciplines. " The concepts of sustainability have often been pigeonholed into graduate level courses in Industrial Ecology or Green Engineering. ${ }^{2}$ Environmental engineering and chemical engineering textbooks may cover some basics concepts of sustainability, but the extend and breadth of knowledge is insufficient to meet the multifaceted demand associated with engineering sustainable processes and products. ${ }^{3}$

Crittenden suggests that sustainable solutions include the following important elements/steps: (a) translating and understanding societal needs into engineering solutions such as infrastructures, products, practices, and processes; (b) explaining to society the long-term consequences of these engineering solutions; and (c) educating the next generation of scientists and engineers to acquire both the depth and breadth of skills necessary to address the important physical and behavioral 
science elements of environmental problems and to develop and use integrative analysis methods to identify and design sustainable products and systems. ${ }^{4}$

Unfolding environmental events, like the recent flooding in New York, the BP oil spill in the Gulf of Mexico, and our changing climate, mean that sustainability courses will increasingly be desired in engineering fields. Sustainability courses are already a requirement for most graduates of EU, Chinese, and Indian engineering programs. Chemical engineering, construction engineering, energy engineering, industrial engineering and mechanical engineering, which have not historically included a required environmental engineering course, will require a fundamental understanding of sustainability indicators and metrics in order to stay relevant in international opportunities. Sustainability is most commonly covered in existing environmental engineering courses, however these courses are typically limited to civil and environmental engineering majors. ${ }^{5}$ Introductory environmental engineering courses often have objectives focused more upon historical perspectives in remediation and large-scale treatment systems than upon forwardlooking sustainability concepts.

The Association for the Advancement of Sustainability in Higher Education (AASHE) compiles data for programs that identify sustainability focused curriculum, as shown in Table $1{ }^{6}$ In spite of the large number of existing programs, there is no consensus yet as to the curriculum requirements for implementation of sustainable design practices across undergraduate engineering programs. ${ }^{7}$ The suitability sequence described herein introduces applications of fundamental environmental science and sustainability indicators that are being broadly adopted by industry and organizations to make informed resource management and design decisions.

Table 1: Self-identified sustainability-focused programs listed by AASHE in $2013^{8}$

\begin{tabular}{|l|r|r|}
\hline \multicolumn{1}{|c|}{ Level/degree of the program } & Number of programs & Engineering programs \\
\hline Associate Degree & 30 & 4 \\
\hline Baccalaureate Degree & 417 & 63 \\
\hline Joint Degree & 34 & 1 \\
\hline Specialization/Concentration/Emphasis & 17 & 2 \\
\hline Minor & 146 & 14 \\
\hline Undergraduate Certificate/Diploma & 48 & 7 \\
\hline Graduate Certificate/Diploma & 135 & 10 \\
\hline Masters Degree & 448 & 84 \\
\hline Doctoral Degree & 103 & 59 \\
\hline Post-Graduate Certificate/Diploma & 32 & 1 \\
\hline
\end{tabular}

The sustainability-focused curriculum

In December of 2005, a University task force was created to develop an engineering program at the university. The program was developed to fit ABET's General Engineering student outcomes (a) through (k), listed below:

\section{a. Ability to apply mathematics, science and engineering principles.}


b. Ability to design and conduct experiments, analyze and interpret data.

c. Ability to design a system, component, or process to meet desired needs.

d. Ability to function on multidisciplinary teams.

e. Ability to identify, formulate and solve engineering problems.

$f$. Understanding of professional and ethical responsibility.

g. Ability to communicate effectively.

$h$. The broad education necessary to understand the impact of engineering solutions in a global and societal context.

$i$. Recognition of the need for and an ability to engage in life-long learning.

$j$. Knowledge of contemporary issues.

$k$. Ability to use the techniques, skills and modern engineering tools necessary for engineering practice.

Recommendations from the National Academy of Engineering and ideas from faculty, industry representatives, and the popular literature were combined with ABET accreditation standards and requirements from the Fundamentals of Engineering (FE) examination were used as a basis for the general engineering curriculum. The task force developed a list of desired learning objectives and educational outcomes for the new degree program. Using the ABET accreditation criteria and the FE licensure exam as guidelines, more than 200 detailed learning objectives were developed and mapped to the individual courses in the new curriculum.

The inaugural freshman class was accepted in August 2008. The new engineering program offers a single, interdisciplinary engineering bachelor's degree that is designed to meet ABET accreditation standards and prepare graduates for the FE examination. In addition to the ABET and FE standards, the engineering program was created to emphasize and develop engineering graduates that understand and can utilize the concepts of sustainability in conjunction with standard engineering analysis and design curriculum components. The engineering program has developed a two-course sequence of sustainability-focused courses focused on the engineering applications of sustainability science, environmental impact analysis, and applications of models of sustainability, such as Green Building analysis and Life Cycle Analysis (LCA). The twocourse sequence was developed to address the mission statement of the department:

Department of Engineering graduates will improve the sustainability of our world by analyzing problems and designing solutions in the context of technical, economic, environmental, and social impacts.

The first course "ENGR 411: Fundamentals of Sustainable Engineering and Design" focused on introducing general sustainability concepts and quantifying environmental impacts. The second course, "ENGR 412: Sustainable Engineering \& Design II" focused on material and energy balances and life cycle assessment. The two-course sustainability sequence includes foundational knowledge of environmental impact assessment methods, life cycle analysis, and energy considerations. Prerequisites for such a course are the foundational math courses in calculus, chemistry, and physics. The sustainability sequence was designed for sophomore to senior students in engineering and is applicable to all engineering disciplines. 
There is a tremendous range of courses offered in sustainability related fields, often due to a professor's singular expertise or interest. ${ }^{8,9}$ The authors of this sustainability-focused curriculum have drawn on their various backgrounds in engineering, policy and technology to assemble a comprehensive curriculum on sustainable design and development. Understanding sustainable design and related fields like basic climate science, green building and life cycle analysis will continue to gain importance for practicing engineers and scientists. This sustainability-focused curriculum introduces a new approach to sustainability that includes foundational knowledge of environmental impact assessment methods, life cycle analysis, and energy considerations that are being adopted in many accredited engineering and technology programs. The sustainabilityfocused curriculum is focused upon applying engineering principles to real-world design and problem analysis. It includes specific step-by-step examples and case studies for solving complex problems that appear throughout the two courses. Both courses conceptual and applied problems at various levels of difficulty. Both courses also apply the principles of sustainable design to issues in both low-income and high-income countries.

The topics covered in the ENGR 411 and ENGR 412 sequence include:

- Sustainability, Engineering and Design: Definitions of sustainability

- Fundamentals of environmental impacts

- Biogeochemical cycles

- Impacts on water quality

- Impacts on air quality

- The carbon cycle, mass balances, and energy balances

- Models for Engineering Sustainable Design

- Energy conservation and development

- Industrial Ecology

- Life Cycle Analysis

- Sima Pro LCA modeling

- Engineering for Human Communities: The Social Context of Sustainable Design

This sustainability sequence could be adopted for a two semester sequence in sustainable aspects of deign and engineering, or could be used as a foundational for graduate work in sustainability and engineering. The outcomes expected with the courses were developed by the teaching faculty of the course in conversation with the other engineering faculty of the in the department at that time. Course outcomes were considered based upon several criteria, including, but not limited to:

- The ability to prepare students for the general engineering FE examination;

- Alignment with ABET criteria (a) through (k);

- Coverage of sustainability topics in related textbooks;

- Coverage of topics by government organizations (such as the USEPA), international organizations (such as the UNEP, UNDP, FAO), and professional organizations (such as AWWA, IWA, AASHE, USGBC, etc); and

- Instructor experience. 
The expected course outcomes and related ABET criteria associated with each course are listed in Table 2. The sustainability-focused curriculum is modeled upon the assumption that this will be the first introduction to sustainability and that students have the appropriate mathematical and science foundation for study in engineering. Junior or senior level general engineering students took the sustainability-focused curriculum in this study.

Table 2. Expected outcomes and related ABET criteria for sustainability-focused courses

\begin{tabular}{|c|c|c|c|}
\hline $\begin{array}{l}\text { Outcome } \\
\text { ID }\end{array}$ & Course & Expected Course Outcomes & $\begin{array}{l}\text { Related } \\
\text { ABET } \\
\text { Criteria }\end{array}$ \\
\hline 1 & 411 & $\begin{array}{l}\text { Perform calculations involving conventional units utilized in } \\
\text { engineering }\end{array}$ & $\mathrm{a}, \mathrm{e}$ \\
\hline 2 & 411 & $\begin{array}{l}\text { Solve basic equilibrium problems in environmental chemistry related to } \\
\mathrm{pH} \text { and solubility }\end{array}$ & $\mathrm{a}, \mathrm{c}, \mathrm{e}$ \\
\hline 3 & 411 & $\begin{array}{l}\text { Prepare mass balance equations to determine the impacts of pollutants } \\
\text { upon the environment }\end{array}$ & $\mathrm{c}, \mathrm{e}$ \\
\hline 4 & 411 & $\begin{array}{l}\text { Solve mass balance problems related to determine the impacts of } \\
\text { pollutants upon the environment }\end{array}$ & $\mathrm{a}, \mathrm{c}, \mathrm{e}$ \\
\hline 5 & 411 & $\begin{array}{l}\text { Calculate and describe the impact of anthropogenic emissions on the } \\
\text { oxygen content in natural aqueous environments }\end{array}$ & $\mathrm{a}, \mathrm{c}, \mathrm{e}$ \\
\hline 6 & 411 & Describe the impact of anthropogenic sources on water and air quality & $\begin{array}{l}\mathrm{a}, \mathrm{c}, \mathrm{f}, \mathrm{h}, \\
\mathrm{j}, \mathrm{k}\end{array}$ \\
\hline 7 & 411 & $\begin{array}{l}\text { Describe the relationship between community sustainability, global } \\
\text { climate change, environmental impacts, economic projects, and fossil } \\
\text { fuel emissions }\end{array}$ & $\mathrm{f}, \mathrm{h}, \mathrm{i}, \mathrm{j}$ \\
\hline 8 & 411 & $\begin{array}{l}\text { Develop frameworks for conceptualizing complex, open system } \\
\text { problems, and the inter-relationship of environmental, energy, } \\
\text { economic, health, technological, and cultural factors }\end{array}$ & $\begin{array}{l}\mathrm{c}, \mathrm{f}, \mathrm{h}, \mathrm{i}, \\
\mathrm{j}\end{array}$ \\
\hline 9 & 412 & $\begin{array}{l}\text { Perform calculations involving conventional units utilized in } \\
\text { engineering }\end{array}$ & $\mathrm{a}, \mathrm{e}$ \\
\hline 10 & 412 & $\begin{array}{l}\text { Prepare mass balance equations to track materials flows in } \\
\text { manufactured products and emissions }\end{array}$ & $\mathrm{a}, \mathrm{e}, \mathrm{h}$ \\
\hline 11 & 412 & Solve mass balance problems related to impacts of industrial processes & $\mathrm{a}, \mathrm{e}, \mathrm{h}$ \\
\hline 12 & 412 & $\begin{array}{l}\text { Identify criteria for evaluating social considerations in sustainable } \\
\text { development }\end{array}$ & $f, g, h, j$ \\
\hline 13 & 412 & $\begin{array}{l}\text { Describe the relationship between global, regional and local } \\
\text { environmental impacts, and economic factors }\end{array}$ & $f, g, h$ \\
\hline 14 & 412 & $\begin{array}{l}\text { Predict and feel concern for the biological and environmental effects of } \\
\text { the design of man-made devices }\end{array}$ & $\mathrm{f}, \mathrm{h}$ \\
\hline 15 & 412 & $\begin{array}{l}\text { Develop frameworks for conceptualizing complex, open system } \\
\text { problems, and the inter-relationship of environmental, energy, } \\
\text { economic, health, technological, and cultural factors }\end{array}$ & $\begin{array}{l}\mathrm{b}, \mathrm{c}, \mathrm{e} \\
\mathrm{g}, \mathrm{h}, \mathrm{i}\end{array}$ \\
\hline 16 & 412 & $\begin{array}{l}\text { Implement sustainability tools, such as life cycle assessment when } \\
\text { conducting systems analysis }\end{array}$ & $\mathrm{a}, \mathrm{c}, \mathrm{h}$ \\
\hline 17 & 412 & $\begin{array}{l}\text { Model total material cycles (i.e. product cradle-to-grave life including } \\
\text { design, manufacturing, and disposal phases) when developing products } \\
\text { and processes }\end{array}$ & $\mathrm{a}, \mathrm{h}$ \\
\hline 18 & 412 & Use professional software to perform a basic life cycle assessment & $\mathrm{e}, \mathrm{h}, \mathrm{i}, \mathrm{k}$ \\
\hline
\end{tabular}


Evolution of the sustainability sequence of courses

The sustainability courses were introduced in 2008. The curriculum was originally intended to include two semesters of general chemistry, however, due to enrollment numbers, changes in faculty and other issues, the initial curriculum included only one semester of general chemistry. The first semester of chemistry in many general chemistry textbooks includes only an introduction to the atom, the periodic chart and balancing chemical equations. The second semester, in both textbooks and many curriculum, includes the applications of chemistry, such as chemical equilibrium, acid-base chemistry, thermodynamic principles, and other chemical principles that form the basis of engineering application that require chemistry.

Student grades were measured by typical methods, through homework, quizzes, exams, and student project work. Homework assignments were generally utilized for learning the topics and could be completed in groups. The outcomes were measured through a combination of outcome specific quizzes during the semester and through comprehensive final exam questions. Both quiz questions and final exam questions were mapped to the student outcomes. For the purposes of reporting in this paper, the success of meeting the objectives was grouped into 4 categories: Low, Poor, Medium, or High, based upon the following criteria:

Low $=$ less than $25 \%$ of students graded $85 \%$ or higher on assessment questions Poor $=25$ to $50 \%$ of students graded $85 \%$ or higher on assessment questions Medium $=50 \%$ to $80 \%$ of students graded $85 \%$ or higher on assessment questions High $=$ greater than $80 \%$ of students graded $85 \%$ or higher on assessment questions

The first offering of ENGR 411, the first course in sustainability, required students to prepare in advance by learning the second semester of general chemistry through an eight-week lab based seminar chemistry course. The course was designed with the premise that students would have a basic grounding in chemistry and/or be able to "pick-up" the chemistry principles in the course. Unfortunately, the first several offerings of the ENGR 411 class were greatly impeded by the inability of student's to perform basic operations in chemistry such as using chemical quantities, performing unit conversions, and performing equilibrium calculations. The student outcomes are presented in Table 3. Without these basic chemistry skills, students had great difficulty completing mass balance problems and could not predict the fate or transport of potential compound in the environment. Without this practical analytical ability, students were able to learn and repeat environmental, economic and social concerns at a low-level on Bloom's taxonomy. Students' performance was also poor when asked to use engineering principles to describe why environmental impacts would occur and how environmental impacts might be mitigated. 
Table 3. Levels of achievement in meeting course objectives.

\begin{tabular}{|c|c|c|c|c|c|}
\hline \multirow{2}{*}{$\begin{array}{l}\text { Out- } \\
\text { come } \\
\text { ID }\end{array}$} & \multirow[t]{2}{*}{ Outcome } & \multicolumn{4}{|c|}{ Year } \\
\hline & & 2010 & 2011 & 2012 & 2013 \\
\hline $1 \& 9$ & $\begin{array}{l}\text { Perform calculations involving conventional units } \\
\text { utilized in engineering }\end{array}$ & Medium & Medium & Medium & High \\
\hline 2 & $\begin{array}{l}\text { Solve basic equilibrium problems in environmental } \\
\text { chemistry related to } \mathrm{pH} \text { and solubility }\end{array}$ & Poor & Low & Low & Medium \\
\hline 3 & $\begin{array}{l}\text { Prepare mass balance equations to determine the } \\
\text { impacts of pollutants upon the environment }\end{array}$ & Poor & Low & Medium & High \\
\hline 4 & $\begin{array}{l}\text { Solve mass balance problems related to determine } \\
\text { the impacts of pollutants upon the environment }\end{array}$ & Poor & Low & Medium & Medium \\
\hline 5 & $\begin{array}{l}\text { Calculate and describe the impact of anthropogenic } \\
\text { emissions on the oxygen content in natural aqueous } \\
\text { environments }\end{array}$ & Poor & Low & Medium & High \\
\hline 6 & $\begin{array}{l}\text { Describe the impact of anthropogenic sources on } \\
\text { water and air quality }\end{array}$ & Poor & Low & Medium & Medium \\
\hline 7 & $\begin{array}{l}\text { Describe the relationship between community } \\
\text { sustainability, global climate change, environmental } \\
\text { impacts, economic projects, and fossil fuel emissions }\end{array}$ & Medium & Medium & Medium & Medium \\
\hline 8 & $\begin{array}{l}\text { Develop frameworks for conceptualizing complex, } \\
\text { open system problems, and the inter-relationship of } \\
\text { environmental, energy, economic, health, } \\
\text { technological, and cultural factors }\end{array}$ & Medium & Medium & Medium & Medium \\
\hline 10 & $\begin{array}{l}\text { Prepare mass balance equations to track materials } \\
\text { flows in manufactured products and emissions }\end{array}$ & Low & Medium & Medium & High \\
\hline 11 & $\begin{array}{l}\text { Solve mass balance problems related to impacts of } \\
\text { industrial processes }\end{array}$ & Low & Medium & Medium & High \\
\hline 12 & $\begin{array}{l}\text { Identify criteria for evaluating social considerations } \\
\text { in sustainable development }\end{array}$ & Medium & Medium & Medium & Medium \\
\hline 13 & $\begin{array}{l}\text { Describe the relationship between global, regional } \\
\text { and local environmental and economic factors }\end{array}$ & Medium & Medium & Medium & Medium \\
\hline 14 & $\begin{array}{l}\text { Predict the biological and environmental effects of } \\
\text { the design of man-made devices }\end{array}$ & Medium & Medium & Medium & Medium \\
\hline 15 & $\begin{array}{l}\text { Develop frameworks for conceptualizing complex, } \\
\text { open system problems, and the inter-relationship of } \\
\text { environmental, energy, economic, health, } \\
\text { technological, and cultural factors }\end{array}$ & Low & Medium & Medium & High \\
\hline 16 & $\begin{array}{l}\text { Implement sustainability tools, such as life cycle } \\
\text { assessment when conducting systems analysis }\end{array}$ & Medium & Medium & High & High \\
\hline 17 & $\begin{array}{l}\text { Model total material cycles (i.e. product cradle-to- } \\
\text { grave life including design, manufacturing, and } \\
\text { disposal phases) for products and processes }\end{array}$ & Medium & Medium & High & High \\
\hline 18 & $\begin{array}{l}\text { Use professional software to perform a basic life } \\
\text { cycle assessment }\end{array}$ & Medium & Medium & High & High \\
\hline
\end{tabular}


Once it was demonstrated that the chemistry preparation was insufficient to meet the objectives described by the course and the overall curriculum's mission statement, it was clear that more attention was required with regards to the implementation of chemistry in the curriculum. Since students' were already enrolled and in the midst of completing their degrees, a three part approach was required to adjust the curriculum of ENGR 411:

- Approximately fifty percent of the first sustainability course (ENGR 411) time was devoted to teaching chemistry principles covered in most second semester general chemistry courses. Students who had already completed the required chemistry courses as part of their curriculum took this version of ENGR 411 in 2011.

- Approximately twenty-five percent of the first sustainability course (ENGR 411) time was devoted to teaching chemistry principles covered in most second semester general chemistry courses and other objective received more time. Students who had already not yet completed the required chemistry courses took a 1-credit two-hour special applied chemistry course as part of their curriculum for the version of ENGR 411 taught in 2012.

- Students entering the University in 2011 were required to take either two semesters of general chemistry or AP chemistry and a one credit advanced chemistry course that was added to the University's curriculum. These students began to enroll in ENGR 411 in 2013. The first sustainability course, ENGR 411, in 2013 did a traditional review of some applications of chemistry, but assumed students had command of the principles of chemistry taught in the second semester general chemistry course. The course was offered in a format very similar to the original course design in 2011, additional changes are noted below.

ENGR 412 has been offered since 2010 and various modifications, improvements and redesigns have been introduced to the syllabus based on feedback from student evaluations and teaching assessment polls as well as identified weakness in students' abilities. The most significant course modifications include:

- The time spent on the materials and energy flow analyses modules was increased in order to teach algebraic functions and techniques as this was previously observed to be deficient and a hindrance to proper appreciation of life cycle impact analysis methods.

- The Life Cycle Assessment module, which incorporates the SimaPro LCA software, is now taught over a period of 5 weeks to increase competence and expertise. The modules have been better delineated and are introduced in an incremental manner of complexity to sustain student enthusiasm and interest. Practice exercises have been added and carefully crafted to present easily identifiable and practical problem scenarios.

- The module on energy flow and efficiencies is related to thermodynamic laws covered in ENGR 311 and ENGR 312 which are the departmental thermal sciences classes. The material taught in ENGR 412 has been designed to help contextualize the lessons form the introductory courses and deepen the understanding of the role of thermodynamics in sustainability. Due to this change, ENGR 311 and ENGR 312 are now prerequisite courses for ENGR 412.

The development of a completely new major (there had not previous been an engineering program of any type at this University) may have also impacted student outcomes. For example, 
it was assumed early on by the faculty that students would know the level of effort (class work, home work, reading time, etc.) required to successfully meet course expectations. This assumption was quickly called into question, based upon the performance in 2010. As a result of this performance, the instructor began to require course notebooks and homework be submitted for review in 2011. It was observed that the majority of students did not take class notes, did not take notes from the textbook, and often completed less than $50 \%$ of the assigned homework. These results have been counter to the experiences of the instructors at previous universities, where engineering students generally had much higher rates of completion of the assigned work. It remains uncertain if this is a demographic trend, a function of the students at this specific university, or a function of creating a new program for which an expected work ethic had not yet evolved amongst the student body. Regardless, the instructors found they had to adapt the course in significant ways.

In addition to the changes in the requirements and expectations of a second general chemistry course and thermal sciences prerequisites, there were several other significant changes to the course between 2011 and 2013. Primary among them is the use of a dedicated textbook:

Engineering Applications in Sustainable Design and Development. ${ }^{10}$ Prior to 2013, the course relied on a combination of traditional environmental engineering textbooks and supplemental reading assignments. The new textbook focused specifically on the objectives associated with ENGR 411 and ENGR 412.

The grade assigned to the homework was not significantly altered from 2010 to 2013 . However, with the textbook that provided more illustrated sustainability examples, more time in class was devoted to reviewing the homework. The course was organized along principles that the students may need to be taught study skills that will increase their learning. The course was changed to make the following plan of study explicit to the students. First students would be expected to read the textbook.

Second, students were expected to have completed the workbook, which is an outline of the textbook chapters prior to the start of coverage of that topic on the detailed class schedule. The authors are not able to ascertain whether the students in this particular University and these courses are unique, or whether students rising through a K-12 system that utilizes more explicit assignments and worksheets are more comfortable with a "workbook approach", whatever the reason, students utilized the workbook extensively as a learning tool and study guide. Students would be called upon by name to answer questions in the workbook and explain examples in class.

Third, students would be expected to complete qualitative and quantitative homework problems, if possible prior to class. Fourth, approximately 50 to $75 \%$ of class time was devoted to answering questions about the assigned problems. Homework solutions would be discussed in small groups or by the instructor, as deemed appropriate.

Finally, each outcome was assessed by means of a quiz based upon the related topic. The outcomes were assessed a second time as part of a comprehensive final examination. 
As noted in Table 3, students exhibited much greater understanding of the topics and met at a medium or high level all of the course objectives by 2013.

Summary

As is often the case in dynamic, changing system, it is not possible to distinguish which of the following particular elements played the most important part in meeting the objectives for the sustainability sequence in this curriculum:

- More extensive pre-requisites are required in general chemistry and the thermal sciences;

- Adoption of a course specific textbook;

- Adoption of a workbook as a learning and study aid;

- Literature on sustainability and engineering outcomes was adopted as it became more broadly available;

- Other small changes in teaching style and techniques; or

- Other small changes in student expectations and skills outside the sustainability sequence.

Significant changes in student outcomes were observed with time. The instructors observed that many students did not exhibit the basic study skills required to successfully meet student outcomes. The course was redesigned to teach these study skills through an approach that relied heavily upon the assigned textbook. The current approach also spends much more time on interactive student sessions, than delivering content (now contained in the textbook, but not previously available in a form that was easily accessible to the students.) Unsurprisingly, students were able to successfully complete the outcomes with better academic preparation and successful completion of the required prerequisite subject, especially chemistry. A textbook that closely aligns with course outcomes allowed for more self-directed learning, through assigned reading, completion of a workbook (or handwritten notes based upon the assigned reading and example problems) and completion of assigned homework problems that closely align with examples in the textbook. Study skills required for successful completion of the course were made explicit and taught during class meeting times. Class meeting times focused primarily upon interactive question and answer sessions, assessments based upon expected course outcomes, and finally supplementing and contextualizing the subject matter.

The overarching goals of the sustainability sequence of courses was to provide students not only with a working definition of what sustainability and engineering may mean in context to one another, but also to provide engineering tools to be able to evaluate and predict the impacts of various design choices upon sustainability indicators. The evolution of the sequence of theses course will help meet the department's mission: "Department of Engineering graduates will improve the sustainability of our world by analyzing problems and designing solutions in the context of technical, economic, environmental, and social impacts."

\section{References}

1. Allenby, B. et al. Teaching Sustainable Engineering. 2007. Journal of Industrial Ecology. 11(1)8-10.

2. Davidson, C. I. Preparing future engineers for challenges of the $21^{\text {st }}$ century: Sustainable Engineering. Journal of Cleaner Production. 2010. 18:698-701. 
3. Azapagic, A. et al. How much do engineering students know about sustainable development? The findings of an international survey and possible implications for the engineering curriculum. European Journal of Engineering Education. 2005. 30(1)1-19.

4. Crittenden, J.C. J. Clean Technol. Environ. Policy 2002, 4(1)6-7.

5. Allen, D. et al. Benchmarking Sustainable Engineering Education: Final Report. 2008. EPA Grant Number X383235101-0.

6. The Association for the Advancement of Sustainability in Higher Education (AASHE). www.aashe.org. Accessed January, 2014.

7. Mihelcic, J. et al. Educating engineers in the sustain bale futures model with a global perspective. Civil Engineering and Environmental Systems. 2008. 25(4):255-263.

8. Allenby, B. et al. Sustainable Engineering Education in the United States. 2009. Sustain Sci. 4:7-15.

9. Mihelcic, J., et al. Sustainability Science and Engineering: The Emergence of a New Metadiscipline. Environ. Sci. Technol. 2003. 37, 5314-5324.

10. Striebig, et al. 2015. Engineering Applications in Sustainable Design and Development. Cengage Publishing. 2015. ISBN: 9781133954958. 